\title{
Editorial to Echocardiographic assessment of left atrial ejection force and kinetic energy in chronic congestive heart failure
}

\author{
Leo H. B. Baur
}

Received: 8 April 2007/Accepted: 8 April 2007/Published online: 14 June 2007

(C) Springer Science+Business Media B.V. 2007

Keywords Left atrial function · Heart failure . Echocardiography

It is well known, that the left atrium plays an important role in filling of the left ventricle: In first instance by being a reservoir of expansion during systole, than by being a conduit phase during diastole and finally by an active phase (if sinus rhythm is present) during late diastole [1]. This active phase has an important role in compensation of decreased left ventricular compliance in patients with heart failure. It is well known, that cardiac output decreases with $15-20 \%$ in patients who are in atrial fibrillation or are only paced in the ventricle [2]. This is not only of importance from pathophysiological point of view, but left atrial function is also an independent determinant of prognosis in patients with heart failure [3]. Stretch of the left atrium is generally controlled by intra-atrial pressure. The FrankStarling mechanism of the left atrium can be described by a biphasic increase of contraction force after increase of the stretch level.

Left atrial function has been investigated with echocardiography for a long time [4].

L. H. B. Baur $(\bowtie)$

Department of Cardiology, Atrium Medical Centre

Parkstad, Henri Dunantstreet 5, Heerlen 6401CX,

The Netherlands

e-mail: 1br01@atriummc.nl
One can make simple measurements of left atrial size or left atrial volume but also try to quantify left atrial function with Doppler and tissue Doppler. During heart failure, atrial function is characterised by augmented reservoir and pump function. This can be measured with pulsed wave Doppler across the mitral valve, which is generally expressed by a decreased E/A ratio. However, there is a marked heterogeneity among heart failure patients with pseudo normal patterns and restrictive filling patterns. This makes it difficult to use pulsed wave Doppler as a determinant of prognosis and guide therapy. The current paper of Tripokiadis et al. [5], describes the measurement of left atrial ejection volume and left atrial ejection force in patients with heart failure. The method is not new and has been described in normal volunteers and patients with atrial fibrillation [6]. Although there were some limitations of the study in sample size, matching of age groups and gender, the authors were able to demonstrate, that left atrial function increases during heart failure and so compensated the decrease of left ventricular function. The model, described by Tripokiadis et al. can be used to estimate atrial function in patients with systolic and diastolic left ventricular dysfunction but also to evaluate the influence of atrial contribution to ventricular filling after medical treatment. Doing so, individual treatment can be optimised not only taking into account the clinical status, renal status, ventricular remodelling and neurohormonal status (BNP), but also atrial contribution to left ventricular filling. 


\section{References}

1. Stefanadis C, Dernellis J, Toutouzas P (2001) A clinical appraisal of left atrial function. Eur Heart J 22:22-36

2. Stefanadis C, Dernellis J, Toutouzas P (1999) Evaluation of left atrial performance using acoustic quantification. Echocardiography $16: 117-125$

3. Sabharwal N, Cemin R, Rajan K, Hickman M, Lahiri A, Senior R (2002) Usefulness of left atrial volume as a predictor of mortality in patients with ischemic cardiomyopathy. Am J Cardiol 94:760-763
4. Hirata T, Wolfe SB, Popp RL, Helmen CH, Feigenbaum H (1969) Estimation of left atrial size using ultrasound. Am Heart J 78:43-52

5. Triposkiadis F, Harbas C, Sitifadis G, Skoulagiris J, Demopoulos V, Kelepeshis G (2007) Echocardiographic assessment of left atrial ejection force and kinetic energy in chronic heart failure. Int J Card Imaging

6. Manning WJ, Silverman DI, Katz SE, Douglas PS (1993) Atrial ejection force: a non-invasive assesment of atrial systolic function. J Am Coll Cardiol 22:221-225 